\title{
Contribuições da Educação Ambiental para o fortalecimento das Colônias de Pesca Z1 e Z2 para atuarem na mediação entre os órgãos governamentais e os pescadores artesanais
}

\author{
Contribuciones de la Educación Ambiental para el fortalecimiento de las \\ Colonias de Pesca Z1 y Z2 para actuar en la mediación entre los \\ organismos gubernamentales y los pescadores artesanales
}

\section{Contributions of Environmental Education for the strengthening of Z1 and Z2 Fishing Colonies to mediate between government agencies and artisanal fishermen}

\author{
Felipe da Silva Justo ${ }^{1}$ \\ Luciana Adélia Sottili² \\ Daniela Benevides Essy ${ }^{3}$
}

\begin{abstract}
Resumo
Neste artigo objetiva-se tecer considerações sobre a importância da mediação, para criação de canais de diálogo entre as instituições e os pescadores artesanais das cidades de Rio Grande e São José do Norte, pautados nas perspectivas da Educação Ambiental, com o apoio de projetos de extensão como o CIDIJUS - Cidadania, Direitos e Justiça da Universidade Federal do Rio Grande (FURG), vinculado a Faculdade de Direito (FADIR), permitindo a manutenção da integração destes com o ecossistema regional, bem como para fomentar a imprescindibilidade de associações fortalecidas, para que possam efetivamente representar a classe e se fazerem capazes de compelir as instituições ao diálogo, para respaldar e apoiar seus associados juridicamente, visando alcançar soluções aos desafios impostos aos pescadores pela contemporaneidade e demais impactos ambientais que afetam o ecossistema lacustre, onde exercem suas atividades falimentares.
\end{abstract}

Palavras-Chave: Associações; Colônias de Pesca; CIDIJUS; Educação Ambiental; Pesca Artesanal.

\section{Resumen}

En este artículo se pretende hacer consideraciones sobre la importancia de la mediación, para la creación de canales de diálogo entre las instituciones y los pescadores artesanales de las ciudades de Rio Grande y São José do Norte, pautados en las perspectivas de la Educación Ambiental, con el apoyo de proyectos de proyectos (FURG), vinculado a la Facultad de Derecho (FADIR), permitiendo el mantenimiento de la integración de éstos con el ecosistema regional, así como para fomentar la imprescindibilidad de asociaciones fortalecidas, para que puedan efectivamente representar a la clase y hacerse capaces de obligar a las instituciones al diálogo, para respaldar y apoyar a sus asociados jurídicamente, buscando alcanzar soluciones a los desafíos impuestos a los pescadores por la contemporaneidad y demás impactos ambientales que afectan el ecosistema lacustre, donde ejercen su trabajo .

Palabras claves: Asociaciones; Colonia de Pesca; CIDIJUS; Educación ambiental; Pesca Artesanal.

Abstract

\footnotetext{
${ }^{1}$ Mestrando em Educação Ambiental - FURG; Rio Grande, Rio Grande do Sul, Brasil; felipejusto@ furg.br

${ }^{2}$ Mestre em Direito e Justiça Social - FURG; Rio Grande, Rio Grande do Sul, Brasil; lusottili@ hotmail.com ${ }^{3}$ Mestranda em Direito e Justiça Social - FURG; Rio Grande, Rio Grande do Sul, Brasil; daniela.benevides@outlook.com
} 
In this article, the goal is to generalize about the importance of mediation, to create channels of dialogue between the institutions and artisanal fishermen of the cities of Rio Grande and São José do Norte, lined in perspectives of environmental education, with the support of extension projects as the CIDIJUS - Citizenship, rights and Justice at the Federal University of Rio Grande (FURG), linked to the Faculty of Law (FADIR), allowing the maintenance of their integration with the regional ecosystem, as well as to foster the indispensability of strengthened associations, so that they can effectively represent the class and become capable of compelling institutions to dialogue, in order to support and support its members legally, in order to reach solutions to the challenges imposed on artisanal fishers by contemporaneity and other environmental impacts that affect the lake ecosystem, where they exert their labor activities.

Keywords: Associations; Fishing Colonies; CIDIJUS; Environmental Education; Artisanal Fishing.

\section{Introdução}

Pretende-se com o presente trabalho apontar a importância da Educação Ambiental para oferecer alternativas viáveis à manutenção das atividades dos pescadores artesanais de Rio Grande/RS e São José do Norte/RS, dado que a atividade garante a sobrevivência de inúmeras famílias, assim como apontar a importância do fortalecimento das Associações de Pescadores, no caso a Colônia de Pesca Z-1 e a Colônia de Pesca Z-2. Tal destaque às associações é necessário, dado o seu ativismo frente aos desafios impostos pela contemporaneidade impostos aos pescadores artesanais e a forma tradicional como exercem suas atividades.

Neste sentido, a referida associação exsurge como um anteparo protetor e um ponto de conexão entre os pescadores, que estão comumente dispersos e assim, são frágeis sem o apoio que a Associação oferece, portanto, buscar-se-á demonstrar que a existência e fortalecimento das Colônias é essencial para manter e fortalecer a união desta classe trabalhadora, permitindo que se consolide, igualmente, como um grupo de enfrentamento ao desfalecimento da seguridade social, aos excessos do poder punitivo estatal e no apoio à conscientização política, ambiental e social.

Deste modo, a Educação Ambiental é apontada como possibilidade de transformação ativa da realidade e das condições da qualidade de vida, fundada em uma conscientização advinda da prática social reflexiva embasada pela teoria (LOUREIRO, 1998), no intuito de estimular a racionalidade moral e ecológica, na promoção de atitudes e valores que permitam a conciliação entre as dicotomias existentes na sociedade, permeada de desigualdades, visando alcançar, sempre que possível, a solução das problemáticas cotidianas através da mediação de conflitos, visando celeridade e eficiência no atendimento das demandas originárias não apenas da atividade pesqueira em si, mas de todo o contexto que engloba a vida dos pescadores artesanais.

Assim, parte-se do pressuposto de que as Colônias de Pescas são essenciais para se 
alcançar todos os pescadores com a máxima eficiência, no intuito de garantir o enfrentamento dos desafios impostos pela contemporaneidade, tais como a fragilização das instituições sociais e a globalização dos ideais de sociedade vigentes no país, elementos que colocam em risco o contexto social, cultural e econômico das comunidades pesqueiras, bem como degradam ambientalmente seus territórios tradicionais de pesca.

\section{A Pesca Artesanal}

A pesca é uma das atividades humanas mais antigas de extrativismo, praticada pelo homem desde a pré-história, com intuito de obter alimentos necessários à sua subsistência a partir do meio aquático.

Mas além da importância para a subsistência humana, a pesca é uma atividade econômica importante, implicando em várias outras atividades complementares, como o transporte, armazenamento, transformação e venda dos produtos da pesca, construção e reparação das embarcações de pesca, construção de artes e utensílios de pesca, gerando renda e empregando pessoas nas atividades indiretas.

Entretanto tal atividade também sofreu influências do advento da modernidade, de forma que a pesca manual, em pequena escala, foi substituída pela pesca industrial, visando o lucro, em detrimento ao meio ambiente, gerando impactos sem precedentes nos ecossistemas marítimos e lacustres. Para coibir determinadas práticas predatórias, existem acordos internacionais, como por exemplo, o acordo internacional para regulamentar a caça às baleias azuis, ratificado pelo Brasil, vigente a partir de 1973 (BRASIL, 1973).

O grande problema é a percepção que a espécie humana tem da natureza, em que a sociedade se exclui do ecossistema, sem vinculação à natureza, como se dela não fizesse parte, tal qual aponta, Guimarães $(1995$, p. 12) quando discorre sobre o homem e a natureza:

Nas sociedades atuais o ser humano afasta se da natureza. [...] O ser humano, totalmente desintegrado do todo, não percebe mais as relações de equilíbrio da natureza. Age de forma totalmente desarmônica sobre o ambiente, causando grandes desequilíbrios ambientais [...].

Com essa compreensão do agir dos homens e mulheres da nossa sociedade, baseado no extrativismo e consumo desenfreado, o qual promove um esgotamento dos "recursos", percebeu-se o risco que o planeta, e por consequência, a espécie humana, corria, de forma que novas propostas surgiram, visando a "preservação", mas apenas para garantir o consumo, e através disso, desencadear o aumento das desigualdades, pois apenas uma fração de pessoas usufrui com os lucros adimplidos nessa exploração desenfreada. Isto por que as formas de 
poluição são diversas, e cada agente contribui de um modo, nas capacidades que lhe cabem, de forma que é absurdo comparar uma mineradora poluidora com um pequeno pescador que enceta sua atividade em período proibido (defeso): são atividades que poluem e afetam o equilíbrio natural, mas devem ser observadas em perspectivas baseadas na proporcionalidade do dano, como aponta Reigota (2009, p. 50) acerca dessa situação, ao dizer que "os impactos ambientais que provocamos com o nosso estilo de vida são diferentes e diferenciados e precisam ser enfatizados e não camuflados na afirmativa simplificadora de que 'o homem destrói o meio ambiente'.” (grifo do autor).

Observar-se, tal como é praticada, sem o viés predatório e potencialmente agressivo que é costumeiro da atividade industrial, onde se utilizam de redes de arrasto que tocam o solo subaquático e danificam as espécies vegetais, além do "naturalizado" descarte dos espécimes menores ou não rentáveis, conquanto a pesca artesanal permita uma maior vinculação do pescador ao ambiente que lhe fornece alimento.

Percebe-se que, assim como o consumo consciente, a pesca artesanal garante um modelo que permite a regeneração das espécies alvo, lesando minimamente (se comparado com a pesca industrial) as demais espécies vegetais e animais, além de garantir a existência de um mercado fomentado no consumo consciente.

A grande problemática é garantir que a pesca artesanal receba do Governo Federal o devido tratamento, seja das instituições diretamente conectadas à emissão das autorizações assim como a garantia de sua subsistência nos períodos de proibição.

\section{Importância das Colônias de Pesca}

Conforme levantamento realizado por Garcez e Sánchez-Botero (2005), Rio Grande possui cerca de 3.500 pescadores profissionais artesanais e 1.200 pescadores artesanais sem documentação. Já, São José do Norte possui uma média de 1.200 pescadores profissionais artesanais e 500 pescadores artesanais sem documentação.

Os dois munícipios se sobressaem com grande distância tanto em relação ao número de pescadores artesanais profissionais quanto ao número de pescadores artesanais sem documentação em relação aos demais números de pescadores que compõe os dois grupos no estado do Rio Grande do Sul.

Um estudo mais recente, com base no número de licenças ambientais para pescadores artesanais que realizam sua atividade no estuário da Lagoa dos Patos, concedidas pelo IBAMA, apresentado por Braido (2015) demonstra, todavia, que o número de pescadores artesanais vem decaindo no município de Rio Grande. No ano de 2011, foram emitidas 1.140 
licenças, em 2012 foram emitidas 1.116 licenças e em 2013 foram emitidas 851 licenças. Já em São José do Norte, a média se mantém, sendo constatado que em 2011 foram concedidas 1.213 licenças, em 2012 constatou-se a emissão de 1.575 licenças e em 2013 foram emitidas 1.256 licenças para pescadores artesanais.

Ainda assim, os municípios de Rio Grande e São José do Norte continuam a manter o maior número de pescadores artesanais existentes no Estado.

A Colônia de Pesca Z-1, foi fundada em janeiro de 1913, na Ilha da Torotama, na cidade de Rio Grande, no Estado do Rio Grande do Sul, e seus associados exercem atividades tanto no estuário da Laguna dos Patos quanto na Lagoa Mirim, enquanto a Colônia Z-2, fundada em 02 de janeiro de 1922 (PEREIRA, 2006) está localizada na sede do município de São José do Norte, no estado do Rio Grande do Sul, e seus pescadores associados estão dispersos em mais de 100 quilômetros de extensão territorial, nas diversas comunidades pesqueiras, tanto nas áreas urbana quanto rural.

Em questão de estrutura para seus associados, a Colônia Z-1 se sobressai em relação a Colônia Z-2, principalmente no atendimento médico e odontológico (BRAIDO, 2015). As Colônias são também responsáveis pelo encaminhamento da documentação de regularização da atividade de seus associados.

Em que pese a ulterioridade da fundação em relação à promulgação da Carta Constitucional de 1988, tal organização foi recepcionada plenamente, conforme o artigo $8^{\circ}$ da Constituição (BRASIL, 1988), possuindo, segundo o inciso III do mencionado artigo, autonomia e competência para "defesa dos direitos e interesses coletivos ou individuais da categoria, inclusive em questões judiciais ou administrativas".

A importância do protagonismo da associação, que deve estar sempre alinhada aos anseios dos seus membros, garantindo que seu objetivo seja sempre o bem-estar de sua comunidade, é essencial e basilar para a sua existência. Se perder seu propósito, não há motivo de existir, devendo sair da mera existência para efetivar a práxis que, definida por Freire (1970, p. 40), é “a reflexão e ação dos homens sobre o mundo para transformá-lo". Assim, num contexto de difícil perspectiva como o atualmente posto, conforme Moura (2016, p. 22), os pescadores "estão se organizando de modo a não sucumbirem enquanto categoria profissional diante da crescente poluição das águas e o consequente declínio do chamado recurso pesqueiro". A autora destaca que esse declínio resulta da pesca predatória e industrial, “mudanças climáticas, especulação imobiliária em áreas litorâneas, turismo, dificuldade de acesso às políticas públicas e de compreensão e adequação ao excessivo e, muitas vezes, contraditório regramento para o setor" (MOURA, 2016, p. 22). 
É nesse contexto de organização que se compreende a importância da associação, enquanto gestora, possuindo know-how ${ }^{4}$ e competência para reunir seus associados, dialogando, de forma problematizadora, como proposto por Freire (1982, p. 145), sem que se estabeleça, de fato, uma hierarquia entre uns e outros, mas que sim, se manifeste a conscientização entre educadores e educandos, no contex to de que todos possuem saberes e é possível o compartilhamento para a formação de indivíduos dotados de saberes amplos.

Assim, compreende-se de extrema importância a contribuição da Educação Ambiental ao enfrentamento dos desafios impostos pela contemporaneidade às Colônias de Pesca Z-1 e Z-2, na medida em que, conforme a Lei 11.699, houve o reconhecimento das colônias como órgãos de classe dos trabalhadores do setor artesanal de pesca, obedecendo ao princípio da livre organização, de forma que com o respaldo legal, definindo seu campo de atuação, garantindo que se alcance maior protagonismo no propósito de proporcionar melhorias e atuar ainda mais pelos associados.

\section{A Educação Ambiental Como Auxiliadora para o Protagonismo das Associações e Pescadores Frente aos Desafios da Contemporaneidade}

A educação ambiental deve ser compreendida como propagadora de soluções, não apenas imediatas, mas em longo prazo, no intuito de reformar as políticas sociais para uma perspectiva mais humana, próxima àqueles que podem ser alcançados pelos conhecimentos e saberem disponíveis ao longo da história da humanidade. Como relata Pereira (2006, p. 53):

[...] temos o dever, como educadores, de propor novas possibilidades, quando essa constitui motivo de alienação e mantenedora do status quo, construindo coletivamente conhecimentos, ampliando a compreensão da realidade complexa e chegando a alternativas aceitas como válidas para o grupo ou classe social (grifo da autora).

De modo semelhante, Reigota (1996, p. 18 e 19) afirma que:

A educação ambiental deve orientar-se para a comunidade, para que ela possa definir quais são os critérios, os problemas e as alternativas [...] auxiliar e incentivar o cidadão e a cidadã a participarem da resolução dos problemas e da busca de alternativas no seu cotidiano de realidades específicas [...] influir decisivamente para isso, quando forma cidadãos e cidadãs conscientes dos seus direitos e deveres. Tendo consciência e conhecimento da problemática global e atuando na sua comunidade e vice-versa haverá uma mudança na vida cotidiana que, se não é de resultados imediatos, visíveis, também não será sem efeitos concretos.

Portanto, o ideal é que o conhecimento produzido possa alcançar aqueles que são

\footnotetext{
${ }^{4}$ Conhecimento ou habilidade técnica para realizar algo, experiência prática na sua realização; saber-fazer.

Fonte: https://www.dicio.com.br/know-how/
} 
objeto do estudo, para além das meras deliberações no "mundo das ideias", pois como coloca Reigota (2016, p. 19), o homem e a mulher criam os problemas ambientais e lhes compete buscar a devida solução, não sendo possível delegar essa competência (apenas) para a ciência, políticos ou até mesmo para a vizinha ou o vizinho.

Com o advento da "modernidade", que produz e trás toda uma problemática como poluição, esgotamento de recursos, propagação de doenças, degradação ambiental dos territórios tradicionais de pesca, e que afeta espécies animais e vegetais, como demonstrado por Guimarães (1995, p. 12) ao dizer que "nas sociedades atuais o ser humano afasta-se da natureza. [...] totalmente desintegrado do todo, não percebe mais as relações de equilíbrio da natureza. Age de forma totalmente desarmônica sobre o ambiente, causando grandes desequilíbrios ambientais".

Com essa compreensão do agir dos homens e mulheres da nossa sociedade, baseado nesse modelo de consumo desenfreado, que promove um esgotamento dos "recursos", percebe-se o risco que o Planeta e, por consequência, a espécie humana correm, de forma que novas propostas surgiram visando à "preservação", mas apenas para garantir o consumo e, através disso, desencadear o aumento das desigualdades, pois apenas uma fração de pessoas usufrui com os lucros que são adimplidos nessa exploração desenfreada.

Isto porque as formas de poluição são diversas, e cada agente contribui de um modo nas capacidades que lhe cabem, de forma que é absurdo comparar a pesca industrial com o pescador artesanal, que enceta sua atividade predatória com um impacto significativamente menor: são atividades que poluem e afetam o equilíbrio natural, mas devem ser observadas em perspectivas baseadas na proporcionalidade do dano. Sobre isso, Reigota (2009, p. 50) afirma: "Os impactos ambientais que provocamos com o nosso estilo de vida são diferentes e diferenciados e precisam ser enfatizados e não camuflados na afirmativa simplificadora de que 'o homem destrói o meio ambiente"'. (grifo do autor)

É neste debate que se insere a Educação Ambiental, pois sua importância advém de uma crise de vínculo em que o ser humano se tornou incapaz de perceber o que o liga ao animal, à natureza, embora este indivíduo seja incapaz de existir sem aquilo (animais e natureza) que não lhe é percebido, do que resulta a atual crise socioambiental, como evidenciado por François Ost (1995). Dessa forma, necessita-se, através da Educação Ambiental, a instauração de uma outra racionalidade que estabeleça um pensamento organicista, de reconhecimento ao mundo a que pertencemos, como seres dependentes, e que demonstre a necessidade de buscar e manter um equilíbrio ecológico. 
Fundamentado essa importância da Educação Ambiental no que se refere à pesca artesanal, denota-se necessário buscar desenvolver não apenas uma compreensão do que as colônias de pesca representam e a sua importância para o enfrentamento dos desafios vivenciados pelos pescadores membros, mas também de valorização dos seus conhecimentos e saberes de modo a fortalecer o campo da educação ambiental. Como bem apontou Pereira (2006, p. 47): "o sucesso do associativismo coloca em pauta a necessidade de se observar os pré-requisitos mínimos para alguém poder ser considerado cidadão, a possibilidade de sobrevivência material e cultural”. Tal fortalecimento é essencial, inclusive para que se possa alcançar o necessário protagonismo da associação, no intuito de que sua existência alcance o máximo de pescadores artesanais, mas que também se torne um modelo na região, no sentido de gestão, apoio e enfrentamento, resistindo e garantindo que, além dos pescadores, todos os demais indivíduos da comunidade percebam sua importância.

Portanto, a proposta de fortalecer a instituição encontra respaldo também no que se refere à fiscalização dos solicitantes de seguro-defeso, no intuito de se garantir as fraudes, que fragilizam as políticas de auxílio, de tal modo que acabam justificando a implementação de burocracias que atrasam o recebimento dos benefícios requeridos pelos que realmente são dependentes do valor pecuniário pago pela seguridade social. Tal situação é apontada por Pereira (2006, p. 90), ao relatar que:

[com] o aumento do desemprego e da miséria no país, muitos se voltam à pesca para sobrevivência, outros se dedicam a atividades pouco honestas buscando os benefícios que essa classe conquistou. É o caso de pessoas que se apresentam como despachantes e "arranjam" documentos necessários para que um cidadão possa usufruir o seguro desemprego que é oferecido ao pescador [...]. Esse fato causa um inchaço no número de pessoas que se dizem pescadores, já que, segundo denúncias, há pessoas de posse usufruindo dos benefícios da pesca.

Nesse pressuposto, é perceptível que uma parceria entre as colônias de pesca e o Instituto Nacional do Seguro Social - INSS, por exemplo, possibilitaria uma lisura no processo administrativo de concessão do seguro-defeso, obedecendo ao teor das legislações ${ }^{5}$ regulamentadoras.

Tal situação foi observada nas ações civis públicas - $\mathrm{ACP}^{6}$ propostas pelas Colônias Z-1 e Z-2 para a obtenção e a emissão dos registros de pescadores e posterior recebimento do seguro-defeso. Essa atuação em um procedimento judicial contencioso, respaldado conforme disposto no artigo $8^{\circ}$, inciso III, da Constituição Federal (BRASIL, 1988), denota um dos exemplos em que se faz imprescindível que a associação seja devidamente fortalecida para

\footnotetext{
${ }^{5}$ Lei no 10.779 , de 25 de novembro de 2003, e Decreto no 8.424, de 31 de março de 2015.

${ }^{6}$ AÇÃO CIVIL PÚBLICA No 5004717-28.2018.4.04.7101 e 5004435-87.2018.4.04.7101.
} 
que possa beneficiar os pescadores da região, até mesmo aqueles não vinculados. $\mathrm{O}$ advento da procedência nas ações civis da associação é uma vitória para toda a coletividade.

\section{A Mediação Como Meio Para Auxiliar os Pescadores e as Associações no Diálogo com as Instituições}

As colônias de pesca são as principais agentes no encaminhamento da documentação da atividade de pesca artesanal de seus associados. Além da função, cabe a elas a promoção de atividades que resultem no acesso a direitos de efetivação da cidadania dos pescadores artesanais e seus familiares.

No entanto, a estrutura que estas possuem (notadamente a Z-2) se mostra deficitária conforme indicado por Adomilli (2007, apud Braido, 2015), pois a precariedade de equipamentos e funcionários não permite que se faça um controle mais organizado e completo que se permita saber o número exato de pescadores no município.

As parcas atividades de promoção de direitos, aliadas ao desconhecimento das engrenagens que movem a burocracia pública, favorecem a diminuta busca e real participação dos pescadores em suas respectivas colônias de pesca e consequentemente reduzem seu acesso a direitos como o encaminhamento do seguro defeso uma vez que para a percepção deste, é necessário o atendimento de requisitos nem sempre cumpridos pelos pescadores artesanais, seja por falta de acesso, seja por desconhecimento.

Desta forma, torna-se imprescindível a promoção de atividades que objetivem o fortalecimento das colônias de pesca e fomentem a construção de uma organização que solidifique sua atuação com a participação ativa dos pescadores de Rio Grande e São José do Norte.

É neste ínterim que projetos de extensão como o CIDIJUS - Cidadania, Direitos e Justiça da Universidade Federal do Rio Grande (FURG), vinculado a Faculdade de Direito (FADIR) pode trazer concretamente mudanças para os pescadores da região.

Agindo através das Colônias de Pesca, o CIDIJUS que se compõe de Professores Doutores do Quadro da Fadir, pesquisadores mestres e mestrandos e alunos da graduação que exercem seus estágios de conclusão de curso no Laboratório de Prática Jurídica, se coloca à disposição dos pescadores para esclarecer suas dúvidas e oferecer o suporte jurídico necessário para a consecução de sua atividade laboral.

A ação do CIDIJUS se compõe de duas frentes principais, a primeira, a) disponibilização de um dia da semana (terças-feiras) para atendimento dos pescadores e seus familiares para esclarecimento de dúvidas jurídicas e encaminhamento para instauração de 
processo caso necessário; b) segunda, a realização de saídas de campo nos finais de semana, em parceria com a Prefeitura Municipal e as Colônias de Pesca, para ouvir os pescadores que por motivos diversos não podem comparecer durante a semana no Laboratório de Prática Jurídica.

Ouvir os pescadores e suas demandas resultou primeiramente na identificação da dificuldade que estes estavam tendo para emissão de sua carteira profissional (RGP) por motivos diversos que denotam o desaparelhamento estatal nos órgãos de auxílio, como a extinção do Ministério da Pesca e Aquicultura em 2015. Desde o ano de 2013 os pescadores enfrentaram inúmeras dificuldades para a emissão e renovação de seu RGP ou outro em substituição que culminaram no aumento do número de pescadores artesanais informais e na impossibilidade de acesso ao seguro defeso.

Em consequência, com o apoio e representação dos professores e advogados que laboram voluntariamente no CIDIJUS, as Colônias de Pesca Z-1 e Z-2, na qualidade de representantes dos pescadores de Rio Grande e São José do Norte, respectivamente, ingressaram com a Ação Civil Pública no 5004435-87.2018.4.04.7101/RS exigindo, dentre outros, a análise dos pedidos de RGPs de todos os pescadores desde 2013 e a intimação do INSS local para que avalie e reavalie os pedidos de seguro-defeso solicitados a partir de 2013, tendo em vista a falta de registro destes pescadores, não como uma falha do indivíduo em apresentar a documentação correta, mas como uma falha do próprio Estado em garantir a estes o direito ao reconhecimento de sua atividade como pescador artesanal.

A audiência de conciliação resultou em um acordo parcial para reapreciação de todos os pedidos de seguro-defeso referentes ao ano de 2018 e a possibilidade dos pescadores ingressarem com ação própria para pedido de revisão dos requerimentos e reparação civil e/ou patrimonial por ausência de concessão de seguro defeso dos anos de 2017 e anteriores.

A aproximação e consequente ação de reivindicação e proteção de direitos dos pescadores artesanais dos municípios de Rio Grande e São José do Norte por parte do CIDIJUS só se mostraram possíveis a partir da mediação das colônias Z-1 e Z-2 com os pescadores, fazendo com que estes pudessem confiar suas angústias e demandas aos componentes do CIDIJUS.

A atuação das colônias Z-1 e Z-2 como mediadora de saberes e ações para a concretização dos direitos de cidadania aos pescadores artesanais se demonstra, portanto, fundamental, pois é a partir das colônias que projetos como CIDIJUS conseguem se aproximar da comunidade e ouvir seus interesses. É através das colônias, atuando com o peso 
da representatividade de associação, que os pescadores artesanais podem ver seu pleito jurídico contemplado com maior celeridade e força.

\section{Conclusões}

Como apontado, por meio do apoio jurídico do CIDIJUS e com o respaldo teórico e prático da Educação Ambiental, utilizando-se de estruturas de mediação existentes nos meios administrativos dos órgãos públicos, garantindo que se promova o resgate e a manutenção de toda uma cultura pesqueira, com a adequada integração dos pescadores artesanais à compreensão da sua importância para o fim de se manter e garantir um extrativismo com menor índice de danos ao ecossistema lacustre nas cidades de Rio Grande/RS e São José do Norte/RS.

Ressalta-se que para além da preservação, é possível uma melhora na qualidade de vida e de renda destes pescadores, uma vez que é possível o desenvolvimento de atividades conexas à pesca, permitindo que mantenham a condição de segurados especiais, auferindo renda mesmo nos períodos de restrição legal. Assim, utilizando os meios pedagógicos, nos âmbitos escolares, acadêmicos e políticos, buscando desenvolver atividades como o ecoturismo, apoio à pesquisa, bem como acesso a cursos e palestras que promovam a troca de experiências entre a práxis dos pescadores e a teoria acadêmica, que contumazmente observa de forma distanciada o desenrolar dos fatos, quando poderia intervir e proporcionar uma rica troca de saberes entre os envolvidos, com salutar incentivo à justiça social, à igualdade e ao desenvolvimento social.

\section{Referências}

BRAIDO, Janaína Agostini. Desencontros legais e morais na pesca artesanal: a educação ambiental política para a transformação socioambiental em Rio Grande/RS e São José do Norte/RS. 2015. 210 f. Dissertação (Mestrado em Educação Ambiental). Universidade Federal do Rio Grande - FURG, Rio Grande. 2015. Disponível em: http://repositorio.furg.br/handle/1/6578. Acesso em 02 de Jan. 2019.

BRASIL. Constituição da República Federativa do Brasil de 1988. Disponível em: http://www.planalto.gov.br/ccivil_03/Constituicao/ConstituicaoCompilado.htm. Acesso em: 20 Set. 2018.

BRASIL. Lei $n^{o} 11.669$, de 13 de Junho de 2008. Dispõe sobre as Colônias, Federações e Confederação Nacional dos Pescadores, regulamentando o parágrafo único do art. 80 da Constituição Federal e revoga dispositivo do Decreto-Lei no 221, de 28 de fevereiro de 1967. Disponível em: http://www.planalto.gov.br/ccivil_03/_ato20072010/2008/lei/111699.htm. Acesso em: 02 de Nov. 2018.

FREIRE, Paulo. Pedagogia do Oprimido. 17. ed. Rio de Janeiro - RJ: Paz e Terra, 1970. 
FREIRE, Paulo. Ação cultural para a liberdade e outros escritos. 6 ed. Rio de Janeiro: Paz e Terra, 1982.

GARCEZ, Danielle Sequeira; SÁNCHEZ-BOTERO, Jorge Iván. Comunidades de pescadores artesanais no estado do Rio Grande de Sul. Atlântica, Rio Grande, RS, v. 1, p.1729, 2005.

GUIMARÃES, Mauro. A Dimensão Ambiental na Educação. Campinas, SP: Papirus, 1995.

LOUREIRO, C. F. B. Reflexões sobre os conceitos de ecocidadania e de consciência ecológica. In: MATA, S.F.da, et al.; (orgs). Educação ambiental, desafio do século: um apelo ético. Rio de Janeiro: Terceiro milênio, 1998. v. 1, p. 119-125.

MOURA, Danieli Veleda. A Organização de Classe dos Pescadores Artesanais da Colônia Z-3 (Pelotas-RS, Brasil) na Luta pela Cidadania e Justiça Ambiental: Contribuições à Educação Ambiental Crítica. 2006. 241 f. Tese (Doutorado em Educação Ambiental) Universidade Federal do Rio Grande - FURG, Rio Grande. 2016. Disponível em: https://sistemas.furg.br/sistemas/sab/arquivos/bdtd/0000011005.pdf. Acesso em 02 de Nov. 2018.

OST, François. A natureza a margem da lei: ecologia à prova do direito. Lisboa: Instituto Piaget, 1995.

PEREIRA, Maria Odete da Rosa. Educação Ambiental Com Pescadores Artesanais: Um Convite À Participação. 2006. 151 f. Dissertação (Mestrado em Educação Ambiental) Universidade Federal do Rio Grande - FURG, Rio Grande. 2006. Disponível em: https://sistemas.furg.br/sistemas/sab/arquivos/bdtd/tde_arquivos/5/TDE-2006-0703T141639Z-31/Publico/Dissertacao\%20Maria\%20Odete.pdf. Acesso em 02 de Nov. 2018.

REIGOTA, M. O que é educação ambiental. 2. ed. revista e ampliada. São Paulo: Brasiliense, 2009. 